\title{
A Direct Aspiration, First Pass Technique (ADAPT) versus Stent Retrievers for Acute Stroke Therapy: An Observational Comparative Study
}

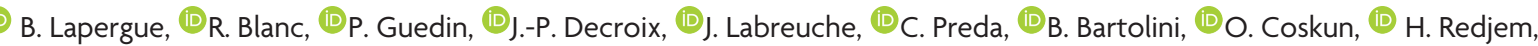

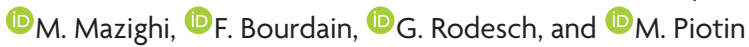

\begin{abstract}
BACKGROUND AND PURPOSE: Mechanical thrombectomy with stent retrievers is now the standard therapy for selected patients with ischemic stroke. The technique of A Direct Aspiration, First Pass Technique for the Endovascular Treatment of Stroke (ADAPT) appears promising with a high rate of recanalization. We compared ADAPT versus stent retrievers (the Solitaire device) for efficacy and safety as a front-line endovascular procedure.
\end{abstract}

MATERIALS AND METHODS: We analyzed 243 consecutive patients with large intracranial artery occlusions of the anterior circulation, treated within 6 hours with mechanical thrombectomy by either ADAPT or the Solitaire stent. Th primary outcome was complete recanalization (modified $\mathrm{TICl} \geq 2$ b); secondary outcomes included complication rates and procedural and clinical outcomes.

RESULTS: From November 2012 to June 2014, 119 patients were treated with stent retriever (Solitaire FR) and 124 by using the ADAPT with Penumbra reperfusion catheters. The median baseline NIHSS score was the same for both groups (Solitaire, 17 [interquartile range, 11-21] versus ADAPT, 17 [interquartile range, 12-21]). Time from groin puncture to recanalization (Solitaire, 50 minutes [range, 25-80 minutes] versus ADAPT, 45 minutes [range, 27-70 minutes], $P=.42$ ) did not differ significantly. However, compared with the Solitaire group, patients treated with ADAPT achieved higher final recanalization rates ( $82.3 \%$ versus $68.9 \%$; adjusted relative risk, $1.18 ; 95 \% \mathrm{Cl}, 1.02-1.37 ; P=.022$ ), though differences in clinical outcomes between the cohorts were not significant. Use of an adjunctive device was more frequent in the ADAPT group ( $45.2 \%$ versus $13.5 \%, P<.0001)$. The rate of embolization in new territories or symptomatic hemorrhage did not differ significantly between the 2 groups.

CONCLUSIONS: Front-line ADAPT achieved higher recanalization rates than the Solitaire device. Further randomized controlled trials are warranted to define the best strategy for mechanical thrombectomy.

ABBREVIATIONS: ADAPT = A Direct Aspiration, First Pass Technique for the Endovascular Treatment of Stroke; $M T=$ mechanical thrombectomy; $\mathrm{mTICl}=$ modified $\mathrm{TICI}$

M

echanical thrombectomy (MT) has now been validated through several large randomized controlled trials in the

Received February 2, 2016; accepted after revision April 18.

From the Division of Neurology (B.L., J.-P.D., F.B.), Stroke Center, Foch Hospital, University Versailles Saint-Quentin en Yvelines, Suresnes, France; Department of Diagnostic and Interventional Neuroradiology (P.G., O.C., G.R.), Foch Hospital, Suresnes, France; Department of Diagnostic and Interventional Neuroradiology (R.B., B.B., H.R., M.P.), Rothschild Foundation, Paris, France; Department of Biostatistics (J.L.), Univiversity of Lille, Centre Hospitalier Universitaire Lille, Santé Publique: Epidémiologie et Qualité des Soins, Lille, France; Laboratoire de Mathématiques Paul Painlevé (C.P.), Unité Mixte de Recherche CNRS 8524, Lille, France; and Department of Neurology and Stroke Center (M.M.), Lariboisière Hospital, Paris, France.

The authors contributed to the article in the following manner: F.B., B.L., R.B, M.P., M.M., J.L. participated in the conception and design of the study; B.L, R.B., F.B., M.P., J.L., M.M., C.P. analyzed and interpreted the data; B.L., F.B., J.-P.D., R.B., P.G., B.B., O.C., H.R., F.B., G.R., M.P. were responsible for the provision of study materials or patients; F.B., B.L., J.-P.D., R.B., M.P. were responsible for collection, assembly, and possession of the raw data; C.P. and J.L. were responsible for statistical expertise; and B.L., R.B., M.P., M.M., F.B. were responsible for drafting the article.

Please address correspondence to Bertrand Lapergue, MD, PhD, Division of Neurology, Stroke Center, Foch Hospital, University Versailles Saint-Quentin en Yvelines, Suresnes, France; e-mail: b.lapergue@hopital-foch.org treatment of acute ischemic stroke due to large-vessel occlusion. ${ }^{1-5}$ These studies demonstrated a major decrease in disability. Successful revascularization has been shown to increase the likelihood of a good clinical outcome. ${ }^{6}$ However, these randomized controlled trials, by using the latest generation of stent retriever devices available at the time, reported successful revascularization rates ranging between $58 \%$ and $72 \%$ in the 2 largest studies. ${ }^{1,3}$ Although the randomized controlled trials proved that MT was beneficial, more than one-third of the procedures resulted in failure to recanalize. ${ }^{7,8}$ Improvement in the rate of successful recanalization is thus a critical issue. The stent retriever procedure starts with the common transfemoral access, followed by the introduction of the stent retrievers via a microcatheter through a balloonguide catheter. The balloon-guide catheter is inflated to create

Indicates article with supplemental on-line appendix and table.

Indicates article with supplemental on-line photo.

http://dx.doi.org/10.3174/ajnr.A4840 
flow arrest while retrieving the stent retrievers. Another approach is A Direct Aspiration, First Pass Technique for the Endovascular Treatment of Stroke (ADAPT), ${ }^{9}$ which involves using front-line aspiration alone to remove the thrombus through a highly trackable, atraumatic, large-bore aspiration catheter. Its success is based on using the largest catheter permitted by the vessel, ensuring greater aspiration power for thrombus extraction. In case of failure with the front-line ADAPT approach, the large-bore aspiration catheter can be used as a conduit for introducing a stent retriever or another adjunctive device; the system is thus versatile.

We aimed to compare the recanalization efficiency, clinical outcome, and complication rate of ADAPT and stent retrievers, 2 strategies of mechanical thrombectomy.

\section{MATERIALS AND METHODS}

A prospective clinical registry was used to consecutively identify and analyze patients with acute ischemic stroke treated at 2 comprehensive stroke centers between November 2012 and June 2014 (EFFECTS Registry, Endovascular Treatment at Foch HospitalRothschild Foundation in Ischemic Stroke). All patients were assessed for the presence of large intracranial artery occlusions of the anterior circulation and received front-line MT by using either the Solitaire (Covidien, Irvine, California) device or ADAPT by using the 5MAX or 5MAX ACE Reperfusion Catheter (Penumbra, Alameda, California) (On-line Appendix). Most patients underwent brain MR imaging in the acute phase. In cases of MR imaging contraindications, brain CT and CT angiography were performed.

\section{Standard Protocol Approvals}

Locally ethics committees and French Data Protection Agency approved the use of patient data for this retrospective analysis.

\section{Inclusion and Exclusion Criteria}

The following criteria were required for inclusion in this study:

- Proximal middle cerebral artery occlusion or intracranial internal carotid artery occlusion, without associated cervical internal carotid artery occlusion/critical stenosis, was present. Patients referred for acute ischemic stroke with cervical internal carotid occlusion/critical stenosis and basilar occlusion were excluded from this study to decrease bias due to the heterogeneity of patients and endovascular approaches.

- Patients were eligible if they were treatable by MT within 6 hours of stroke onset, with bridging therapy (previous IV rtPA) or standalone thrombectomy. The interventional neuroradiologist could, in the case of recanalization failure (modified TICI [mTICI] $<2 \mathrm{~b}$ ) with the ADAPT or the Solitaire system, use another thrombectomy device of the operator's choice (rescue therapy).

\section{Data Collection and Definitions}

Information on patient characteristics, medical history, laboratory and imaging findings, vital signs before treatment, severity of ischemic stroke, and clinical outcome was collected prospectively by using the same structured questionnaire. The severity of the ischemic stroke was assessed by using the NIHSS score at admission and 24 hours later. We defined early neurologic improve- ment as an NIHSS score of $0-1$ at 24 hours or a decrease of at least 4 points in the NIHSS score. Good functional outcome was defined as a 90 -day $m R S$ score of $\leq 2$. Excellent outcome was defined as a 90 -day $\mathrm{mRS}$ score of $\leq 1$. All patients underwent a CT or MR imaging 24 hours after treatment to assess hemorrhagic complications. Symptomatic intracranial hemorrhage was defined according to the ECASS-II (European Co-operative Acute Stroke Study-II) definition: any intracerebral hemorrhage with an increase of at least 4 NIHSS points within 24 hours, or resulting in death. Symptomatic intracranial hemorrhage was assessed in a blinded manner by noninvolved senior neuroradiologists (R.B., H.R.) and vascular neurologists (B.L., J.-P.D.). The blinded assessment of symptomatic intracranial hemorrhage was specifically performed for this study to assess both aspects of mechanical thrombectomy (successful recanalization rate and hemorrhage complications). During the MT procedure, the presence of embolization in a new territory (defined as an angiographic occlusion in a previously unaffected vascular territory observed on the angiogram after clot removal), the time from symptom onset to groin puncture and from groin puncture to maximal mTICI, and the mTICI score were also monitored. The modified Rankin Scale score at 90 days was assessed by trained research nurses unaware of the study group assignments, during face-to-face interviews or via telephone conversations.

\section{Endovascular Procedure}

ADAPT Group. Patients received aspiration thrombectomy by ADAPT by using the 5MAX ACE (Penumbra) as front-line therapy. The detailed technical procedure has been published previously. ${ }^{9}$ In brief, access was achieved through the femoral artery in compliance with the standard of care. Large-bore catheters were placed distally into the internal carotid artery to provide access for the 5MAX ACE aspiration catheter. Adhering to the instructions for use, the 5MAX ACE catheter was advanced to the level of the occlusion over a microcatheter and a microguidewire. Continuous aspiration was then performed by using the Penumbra aspiration pump for at least 90 seconds in all cases. After engagement of the thrombus with the aspiration catheter, the catheter was allowed to aspirate for at least 30 seconds before its withdrawal with the engaged thrombus. Angiography was performed following recovery to evaluate the flow rate. The preceding steps were repeated until successful revascularization to mTICI $2 \mathrm{~b}-3$ was achieved, while adhering to the admissible treatment window $(<6$ hours from stroke onset).The interventional neuroradiologist could, in the case of recanalization failure (mTICI $<2 \mathrm{~b}$ ) with ADAPT, use another thrombectomy device of the operator's choice (rescue therapy).

Solitaire Group. All MT procedures were performed by using the Solitaire FR (Covidien) via the femoral artery approach. Following the instructions for use of the Solitaire FR, a balloon catheter was positioned within the internal carotid artery to allow flow arrest during thrombus retrieval. The Solitaire FR device was delivered through a microcatheter and deployed inside the thrombus. A control angiogram was performed to determine the immediate reperfusion status, and the device was left deployed for a minimum of 3 minutes. Before retrieval of the stent retriever, the 
Table 1: Baseline characteristics in patients with acute ischemic stroke treated by ADAPT or a conventional stent retriever front-line approach ${ }^{\mathrm{a}}$

\begin{tabular}{lccc}
\hline & $\begin{array}{c}\text { Solitaire Group } \\
(\boldsymbol{n}=119)\end{array}$ & $\begin{array}{c}\text { ADAPT Group } \\
(\boldsymbol{n}=124)\end{array}$ & $\boldsymbol{P}$ Value \\
\hline Age (yr) (mean) & $65.5 \pm 14.7$ & $64.3 \pm 15.7$ & .52 \\
Men & $55(46.2)$ & $61(49.1)$ & .64 \\
Medical history & & & \\
$\quad$ Hypertension & $56(47.5)$ & $72(59.0)$ & .073 \\
$\quad$ Diabetes & $7(5.9)$ & $21(17.2)$ & .007 \\
$\quad$ Hypercholesterolemia & $31(26.3)$ & $32(26.2)$ & .99 \\
$\quad$ Current smoking & $20(18.4)$ & $27(22.1)$ & .48 \\
$\quad$ Antithrombotic therapy & $43(36.1)$ & $44(35.8)$ & .95 \\
$\quad$ NIHSS score (mean) & $15.9 \pm 6.1$ & $15.9 \pm 6.5$ & .99 \\
$\quad$ ASPECTS value at admission & $8(7-10)$ & $9(8-10)$ & .64 \\
$\quad$ (median) (IQR) & & & .52 \\
Occlusion site & $32(26.9)$ & $38(30.7)$ & \\
$\quad$ ICA (isolated or tandem with & & & \\
$\quad$ MCA) & $87(73.1)$ & $86(69.3)$ & .001 \\
$\quad$ Isolated MCA & $54(45.4)$ & $82(66.1)$ & \\
Previous use of IV thrombolysis & $235(181-300)$ & $247(206-308)$ & \\
Onset-to-groin puncture time & & \\
$\quad$ (min) (median) (IQR) & & & \\
\hline Note:-IQR indicates interquartile range. & & & \\
a Values are expressed as number (percentages) unless otherwise indicated. &
\end{tabular}

risks with $95 \%$ confidence intervals. We assessed the heterogeneity in outcome effect across centers by using the Breslow-Day test. Comparisons in primary and secondary outcomes were further adjusted for baseline differences (at $P<.20$ in bivariate analyses) by using a Poisson regression model with robust error variance. ${ }^{12}$ Statistical testing was performed at the 2-tailed $\alpha$ level of .05 except for tests of heterogeneity in which an $\alpha$ level of .10 was chosen. Data were analyzed by using SAS software, Version 9.3 (SAS Institute, Cary, North Carolina).

\section{RESULTS}

Two hundred forty-three consecutive patients with ischemic stroke secondary to occlusions of the ICA or MCA were admitted and treated by mechanical thrombectomy at 2 comprehensive stroke centers. Among them, 119 patients were treated by a conventional front-line stent retriever approach, and 124 patients, by ADAPT. Patient characteristics are shown in Table 1, according to the MT approach. Patients treated by the ADAPT approach had more frequent hypertension and diabetes and more often received IV thrombolysis before MT. No significant between-group differences were found with regard to acute stroke severity (assessed by the NIHSS at presentation), arterial occlusion site, or stroke onset-to-groin puncture time.

\section{Successful Recanalization and MT Approaches}

Overall, 184 patients $(75.7 \%)$ achieved a successful revascularization within a median duration of 45 minutes (interquartile range, 26-73) from groin puncture. In univariate analysis, successful revascularization at final angiography was significantly more often achieved in patients treated with ADAPT $(82.3 \%)$ as opposed to the front-line stent retriever approach $(68.9 \%)(P=.015)$ (Table 2). We found no significant heterogeneity in between-group differences across centers $(P=.62$, On-line Figure). After adjustment for baseline differences, the ADAPT approach remained associated with a significant relative increase of $18 \%(95 \%, \mathrm{CI}$, $2 \%-37 \%$ ) in successful revascularization. Notably, a higher rate of use of additional devices occurred in the ADAPT group, $45.2 \%$ ( $n=56)$, versus $13.5 \%(n=16)$ in the Solitaire group, $(P<.0001$, On-line Table). The success rate (TICI 2b-3) of the 56 patients treated by ADAPT first-line and rescue therapy was 39/56 $(69.6 \%)$. However, we found no significant difference in time between groin puncture and recanalization according to the MT procedure (Figure).

\section{Clinical Outcomes and MT Approaches}

We found no difference in clinical efficacy outcomes between the $2 \mathrm{MT}$ approaches in univariate or multivariate analyses (Table 2). Overall, good functional outcomes defined by an mRS of $0-2$ at 90 days occurred in $54.8 \%(n=63)$ in the stent retriever group ary outcomes between the study groups were expressed as relative 
Table 2: Outcomes in ADAPT or Solitaire group

\begin{tabular}{|c|c|c|c|c|c|c|}
\hline Outcomes $^{a}$ & $\begin{array}{l}\text { Solitaire Group } \\
\qquad(n=119)\end{array}$ & $\begin{array}{l}\text { ADAPT Group } \\
(n=124)\end{array}$ & Relative Risk & $P$ Value & Relative Risk $^{\mathrm{b}}$ & $P$ Value $^{\mathrm{b}}$ \\
\hline $\begin{array}{l}\text { Successful revascularization at } \\
\text { final angiogram }\end{array}$ & $82(68.9)$ & $102(82.3)$ & $1.19(1.03-1.38)$ & .015 & $1.18(1.02-1.37)$ & .022 \\
\hline Early neurologic improvement & $61(55.5)$ & $56(57.1)$ & $1.03(0.81-1.31)$ & .81 & $1.00(0.78-1.28)$ & .99 \\
\hline 90-day excellent outcome & $44(38.3)$ & $45(39.1)$ & $1.02(0.73-1.42)$ & .89 & $1.10(0.78-1.56)$ & .58 \\
\hline 90-day favorable outcome & $63(54.8)$ & $61(53.0)$ & $0.97(0.76-1.23)$ & .79 & $1.05(0.82-1.35)$ & .70 \\
\hline 90-day mortality & 20 (17.4) & $26(22.6)$ & $1.30(0.77-2.19)$ & .32 & $1.14(0.64-2.01)$ & .65 \\
\hline ENT & $8(6.8)$ & $7(5.7)$ & - & .70 & - & - \\
\hline $\mathrm{sICH}$ & $7(5.9)$ & $3(2.4)$ & - & .21 & - & - \\
\hline
\end{tabular}

Note:-ENT indicates embolization in a new territory rate; $\mathrm{sICH}$, symptomatic intracranial hemorrhage.

${ }^{a}$ Early neurologic improvement is defined as an NIHSS score $0-1$ at 24 hours or a decrease of $\geq 4$ points in NIHSS scores at 24 hours. Excellent outcome is defined as an mRS score of $\leq 1$; favorable outcome, an $\mathrm{mRS}$ score of $\leq 2$; and successful recanalization, an $\mathrm{mTICl}$ score of $2 \mathrm{~b}-3$ at final angiography.

${ }^{\mathrm{b}}$ Adjusted for between-group differences in hypertension, diabetes, prior IV thrombolysis, and onset-to-groin puncture time (calculated with a robust Poisson regression model).

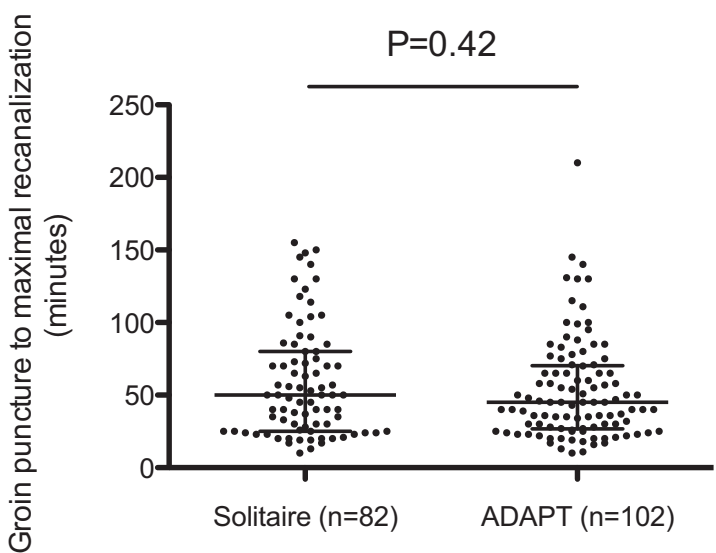

FIGURE. Time from groin puncture to maximal revascularization after a front-line Solitaire stent retriever approach compared with ADAPT. $P$ value for the comparison in time from groin puncture to maximal recanalization is reported (Mann-Whitney $U$ test). Bars indicate the medians with interquartile range values, which were 50 minutes (range, 25-80 minutes) in the Solitaire group and 45 minutes (27-70 minutes) in the ADAPT group.

and $53.0 \%(n=61)$ in the ADAPT group. A total of 46 deaths and 10 symptomatic intracerebral hemorrhages occurred, with no evidence of a difference between the 2 MT approaches (Table 2). Embolization to a new territory caused by MT occurred in $5.7 \%$ $(n=7)$ in the ADAPT group and $6.8 \%(n=8)$ in the Solitaire group $(P=.70)$.

\section{DISCUSSION}

Mechanical thrombectomy by using the latest generation devices has revolutionized the treatment of acute ischemic stroke, in part because the final rate of complete revascularization is higher than recorded rates by using intra-arterial fibrinolysis or the Merci thrombectomy device (Concentric Medical, Mountain View, California). ${ }^{13,14}$ Nevertheless, the rate of revascularization failure remains high, with an occurrence of up to $40 \%$ in large-vessel occlusive strokes. ${ }^{7,15,16}$ Successful reperfusion has been correlated with favorable outcomes. ${ }^{3,6,15,17-22}$ To the authors' knowledge, no studies comparing ADAPT with stent retrievers have been previously published. Assessment of new revascularization strategies is needed to understand how to optimize thrombectomy procedures.

We found that front-line MT by the ADAPT approach achieved a higher rate of complete revascularization at final an- giography than a front-line stent retriever-based strategy $(82.3 \%$ versus $68.9 \%$, adjusted $P=.022$ ). The use of adjunctive devices was higher in the ADAPT group than in the Solitaire group (ADAPT, 38.7\%, versus Solitaire, 13.3\%). Most interesting, this higher rate of adjunctive device use in the ADAPT group did not impact the groin puncture-to-recanalization time $(P=.42$, Fig 1$)$. The benefit of the front-line ADAPT strategy is thus mainly derived from a higher percentage of rescue therapy. One explanation may be related to the ease of setting up a stent retriever through the large-bore aspiration catheter (Solumbra technique). Starting with a $5 \mathrm{MAX}$ ACE, required for the ADAPT technique, thus provides a versatile platform that can readily incorporate devices with different mechanisms of action.

Although the rate of revascularization in the ADAPT cohort was higher, the clinical outcomes did not differ from those in the Solitaire group. This outcome should be interpreted with caution given the comparative observational design of the study.

Periprocedural embolization to a new territory is a concern when performing a mechanical thrombectomy procedure. No differences in rates of embolization in a new territory between ADAPT (5.7\%) and stent retriever (6.8\%) front-line strategies were observed. However, our sample size was limited; experimental work suggests that a combined strategy with aspiration with adjunct stent retrievers may decrease the rate of embolization in a new territory. ${ }^{23}$

Symptomatic hemorrhagic complications, defined in this study as an ECASS-evident intracranial hemorrhage with an increase of $\geq 4$ on the NIHSS scale at 24 hours from baseline, were lower after the ADAPT approach. Study results yielded symptomatic intracranial hemorrhage rates $2.4 \%$ for ADAPT versus $5.9 \%$ for Solitaire) similar to those of recent randomized controlled trials studying stroke. ${ }^{1-5}$ Retrospective studies have reported a high rate of revascularization (TICI $2 \mathrm{~b} / 3>90 \%$ ) with the ADAPT approach, with low complication rates such as $2 \%$ embolization in a new territory and no incidence of symptomatic intracranial hemorrhage. ${ }^{24,25}$

The imbalance of prior rtPA use, which was higher in the ADAPT group (66.1\% versus $45.4 \%$ in the Solitaire group), may have impacted the rate of successful recanalization. However, the adjusted analysis for all confounding factors, including rtPA use, confirms the higher rate of recanalization in the ADAPT group. The direct effect of rtPA use with adjunctive MT remains controversial. $^{26}$

AJNR Am J Neuroradiol 37:1860-65 Oct 2016 www.ajnr.org 
The present findings are derived from observational analyses, which are subject to well-known limitations. The first is the potential for confounding by measured or unmeasured variables, which cannot be ruled out, even after adjustment for baseline between-group differences. The second concerns the potential evaluation bias in clinical outcomes in the absence of blinded evaluation. In addition, no formal study sample size was calculated, and we could not exclude some differences being overlooked due to the lack of adequate statistical power. In a posterior power calculation (not taking into account the adjustment), we calculated the smallest significant between-group difference (expressed as effect size by using relative risk) that our study sample size allowed us to detect with a power of $80 \%$. Assuming an incidence of good outcome of $10 \%$ and $50 \%$ in the reference group (Solitaire), we could respectively detect a relative risk of 2.34 and 1.35 (or 0.43 and 0.74 for a detrimental effect).

We suggest that future studies follow a randomized controlled trial with core imaging performed by an independent neurointerventionalist to further support those findings.

We are currently starting the Interest of Direct Aspiration First Pass Technique (ADAPT) for Thrombectomy Revascularisation of Large Vessel Occlusion in Acute Ischaemic Stroke trial, a randomized, controlled, multicentric, blinded-end-point study (ClinicalTrials.gov, NCT02523261).

\section{CONCLUSIONS}

Front-line ADAPT as an MT strategy achieved higher recanalization rates compared with the Solitaire device, though ADAPT requires higher rates of rescue therapy. Further randomized controlled trials are warranted to define the best strategy for mechanical thrombectomy.

\section{ACKNOWLEDGMENTS}

We thank Mary Osborne-Pellegrin for help in editing the final draft of the manuscript.

Disclosures: Bertrand Lapergue-RELATED: Grant: An institutional grant has been provided by Penumbra for ASTER TRIAL (ADAPT versus stent retriever in acute ischemic stroke); Support for Travel to meetings for the study or other purposes: travel support by Medtronic; Payment for lectures (including service of Speakers Bureaus): speaker's honoraria from Penumbra. Bruno Bartolini-UNRELATED: Consultancy: Stryker Neurovascular. Mikael Mazighi-UNRELATED: Consultancy: Servier, Comments: honoraria for teaching engagements as a consultant; Payment for Lectures (including service on Speakers Bureaus): Covidien; Travel/Accommodations/Meeting Expenses Unrelated to Activities Listed: Bayer A.G., Boehringer Ingelheim, Covidien. Michel Piotin-UNRELATED: Consultancy: Medtronic,* Stryker," MicroVention,* Penumbra*; Payment for Lectures (including service on Speakers Bureaus): Medtronic,* Penumbra*; Grants/grants pending: institutional grants from Stryker, Medtronic, MicroVention, Balt; OTHER: institutional grant from Medtronic for training and proctoring physicians using Pipeline. Raphael BlancUNRELATED: Grants/grants pending: institutional grants from Stryker, Medtronic, MicroVention, Balt; OTHER: institutional grant from Medtronic for training and proctoring physicians using Pipeline. *Money paid to the institution.

\section{REFERENCES}

1. Berkhemer OA, Fransen PSS, Beumer D, et al. A randomized trial of intraarterial treatment for acute ischemic stroke. N Engl JMed 2015; 372:11-20 CrossRef Medline

2. Jovin TG, Chamorro A, Cobo E, et al; REVASCAT Trial Investigators. Thrombectomy within $\mathbf{8}$ hours after symptom onset in ischemic stroke. N Engl J Med 2015;372:2296-306 CrossRef Medline

3. Goyal M, Demchuk AM, Menon BK, et al; ESCAPE Trial Investi- gators. Randomized assessment of rapid endovascular treatment of ischemic stroke. N Engl J Med 2015;372:1019-30 CrossRef Medline

4. Campbell BC, Mitchell PJ, Kleinig TJ, et al; EXTEND-IA Investigators. Endovascular therapy for ischemic stroke with perfusion-imaging selection. N Engl J Med 2015;372:1009-18 CrossRef Medline

5. Saver JL, Goyal M, Bonafe A, et al.; SWIFT PRIME Investigators. Stent-retriever thrombectomy after intravenous t-PA vs. t-PA alone in stroke. N Engl J Med 2015;372:2285-95 CrossRef Medline

6. Khatri P, Yeatts SD, Mazighi M, et al; IMS III Trialists. Time to angiographic reperfusion and clinical outcome after acute ischaemic stroke: an analysis of data from the Interventional Management of Stroke (IMS III) phase 3 trial. Lancet Neurol 2014;13:567-74 CrossRef Medline

7. Smith WS, Sung G, Saver J, et al. Mechanical thrombectomy for acute ischemic stroke: final results of the Multi MERCI trial. Stroke 2008;39:1205-12 CrossRef Medline

8. Kidwell CS, Jahan R. Endovascular treatment of acute ischemic stroke. Neurol Clin 2015;33:401-20 CrossRef Medline

9. Turk AS, Spiotta A, Frei D, et al. Initial clinical experience with the ADAPT technique: a direct aspiration first pass technique for stroke thrombectomy. J Neurointerv Surg 2014;6:231-37 CrossRef Medline

10. Yoo AJ, Simonsen CZ, Prabhakaran S, et al; Cerebral Angiographic Revascularization Grading Collaborators. Refining angiographic biomarkers of revascularization: improving outcome prediction after intra-arterial therapy. Stroke 2013;44:2509-12 CrossRef Medline

11. Zaidat OO, Yoo AJ, Khatri P, et al; Angiographic Revascularization Grading (CARG) Collaborators, STIR Revascularization working group, STIR Thrombolysis in Cerebral Infarction (TICI) Task Force. Recommendations on angiographic revascularization grading standards for acute ischemic stroke: a consensus statement. Stroke 2013;44:2650-63 CrossRef Medline

12. Zou G. A modified Poisson regression approach to prospective studies with binary data. Am J Epidemiol 2004;159:702-06 CrossRef Medline

13. Song D, Kim BM, Kim DJ, et al. Comparison of stent retriever and intra-arterial fibrinolysis in patients with acute ischaemic stroke. Eur J Neurol 2014;21:779-84 CrossRef Medline

14. Broussalis E, Trinka E, Hitzl W, et al. Comparison of stent-retriever devices versus the Merci retriever for endovascular treatment of acute stroke. AJNR Am J Neuroradiol 2013;34:366-72 CrossRef Medline

15. Rha JH, Saver JL. The impact of recanalization on ischemic stroke outcome: a meta-analysis. Stroke 2007;38:967-73 CrossRef Medline

16. Smith WS, Sung G, Starkman S, et al; MERCI Trial Investigators. Safety and efficacy of mechanical embolectomy in acute ischemic stroke: results of the MERCI Trial. Stroke 2005;36:1432-38 CrossRef Medline

17. Campbell BC, Donnan GA, Lees KR, et al. Endovascular stent thrombectomy: the new standard of care for large vessel ischaemic stroke. Lancet Neurol 2015;14:846-54 CrossRef Medline

18. Khatri P, Hacke W, Fiehler J, et al; VISTA-Endovascular Collaboration. State of acute endovascular therapy: report from the 12th thrombolysis, thrombectomy, and acute stroke therapy conference. Stroke 2015;46:1727-34 CrossRef Medline

19. Saver JL, Jahan R, Levy EI, et al; SWIFT Trialists. Solitaire flow restoration device versus the Merci retriever in patients with acute ischaemic stroke (SWIFT): a randomised, parallel-group, non-inferiority trial. Lancet 2012;380:1241-49 CrossRef Medline

20. Nogueira RG, Lutsep HL, Gupta R, et al; TREVO 2 Trialists. Trevo versus Merci retrievers for thrombectomy revascularisation of large vessel occlusions in acute ischaemic stroke (TREVO 2): a randomised trial. Lancet 2012;380:1231-40 CrossRef Medline

21. Tomsick T, Broderick J, Carrozella J, et al; Interventional Management of Stroke II Investigators. Revascularization results in the In- 
terventional Management of Stroke II Trial. AJNR Am J Neuroradiol 2008;29:582-87 CrossRef Medline

22. Sarraj A, Gupta R. Endovascular treatment for ischemic strokes with large vessel occlusion: proven therapy and bright future. Stroke 2015;46:1431-32 CrossRef Medline

23. Chueh JY, Puri AS, Wakhloo AK, et al. Risk of distal embolization with stent retriever thrombectomy and ADAPT. J Neurointerv Surg 2016;8:197-202 CrossRef Medline

24. Turk AS, Frei D, Fiorella D, et al. ADAPT FAST study: a direct aspi- ration first pass technique for acute stroke thrombectomy. J Neurointerv Surg 2014;6:260 - 64 CrossRef Medline

25. KowollA, WeberA, Mpotsaris A, et al. Direct aspiration first pass technique for the treatment of acute ischemic stroke: initial experience at a European stroke center. J Neurointerv Surg 2016;8:230-34 CrossRef Medline

26. Guedin P, Larcher A, Decroix JP, et al. Prior IV thrombolysis facilitates mechanical thrombectomy in acute ischemic stroke. J Stroke Cerebrovasc Dis 2015;24:952-57 CrossRef Medline 